\title{
Cord Blood Screening for Hemoglobin Disorders by High-Performance Liquid Chromatography*,1
}

\author{
Adoor amanullah, Samir Hanash, Kirsten Bunnell, John Strahler, \\ Donald L. Rucknagel, and Steven J. Ferruci \\ Department of Pediatrics and Human Genetics, University of Michigan School of Medicine, \\ Ann Arbor, Michigan 48109
}

Received January 27, 1982

\begin{abstract}
Ion-exchange high-performance liquid chromatography was employed as a screening method for abnormal hemoglobins in the newborn period. Samples of cord blood collected in EDTA tubes were used for this analysis. Hemolysates were injected onto $4.1 \times 100-\mathrm{mm}$ Synchropak ion-exchange columns using an automatic injector. Hemoglobin separation was carried out by means of a sodium acetate gradient. A total of 415 samples was analyzed. Hemoglobins A, F, and Bart's, as well as C or S when present, were separately eluted and quantitated using a 35-min gradient program. Four individuals with sickle cell disease, 26 with $\mathrm{S}$ or $\mathrm{C}$ trait, one with SC disease, and two others with alpha-chain variants were diagnosed with this method. The proportion of Bart's hemoglobin was greater than $1 \%$ in 33 individuals. The elution pattern was highly reproducible. The potential for complete automation and the ease with which quality control can be assured make this technique well suited for the detection of abnormal hemoglobins in the newborn period.
\end{abstract}

Neonatal screening for abnormal hemoglobins provides a practical approach for the detection of sickling syndromes and other hemoglobin disorders such as $\alpha$-thalassemia. Most screening programs utilize various electrophoretic techniques for the detection of abnormal hemoglobins (1-4). Electrophoresis on cellulose acetate at $\mathrm{pH} 8.6$ identifies increased amounts of Bart's hemoglobin $(\mathrm{Hb})^{2}$ associated with alpha thalassemia (1). However, hemoglobins $\mathrm{F}, \mathrm{A}$, and $\mathrm{S}$ are not always well resolved from each other. Electrophoresis on citrate agar at $\mathrm{pH} 6.2$ provides better separation of $\mathrm{Hb} \mathrm{F}$ from $\mathrm{Hb} \mathrm{S}$; however, Bart's $\mathrm{Hb}$ is not easily detectable. Some screening programs utilize both of these techniques because of the limitations

* This paper was presented at the International Symposium on HPLC of Proteins and Peptides, November 16-17, 1981, Washington, D. C.

${ }^{\prime}$ Supported in part by NIH Grant HL25541.

${ }^{2}$ Abbreviations used: $\mathrm{Hb}$, hemoglobin; HPLC, highperformance liquid chromatography. of each when used separately (4). Microcolumn chromatography (5) has also been used for newborn screening. Another recently described technique is thin-layer isoelectric focusing (6). Neither microcolumn chromatography nor isoelectric focusing has been useful for the quantitation of Bart's $\mathrm{Hb}$ (7). Recently ion-exchange high-performance liquid chromatography (HPLC) has been utilized for the separation of hemoglobin types (8). We have therefore investigated the use of HPLC in cord blood screening for hemoglobin disorders.

\section{MATERIALS AND METHODS}

Blood samples. Cord blood samples from black newborns were collected into EDTAcontaining tubes. Red cells were isolated by centrifugation, washed three times with physiological saline, and hemolyzed with equal volumes of distilled water and toluene. The toluene fraction containing cellular de- 


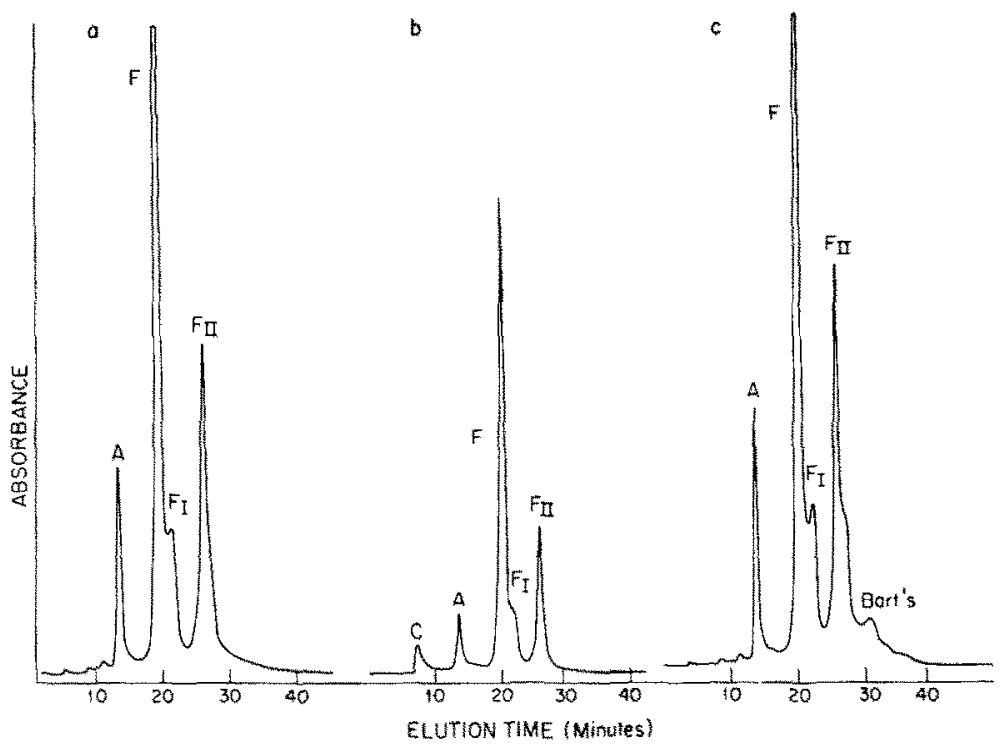

FiG. 1. HPLC separation of hemoglobins in hemolysates from three newborns: (a) normal, (b) HbC trait, and (c) with increased levels of Bart's $\mathrm{Hb}$, using a 35-min gradient-program. Column: Synchropak AX $300,4.1 \times 100 \mathrm{~mm}$. Sample volume: $20 \mu \mathrm{l}$. Gradient parameters: flow rate $1.5 \mathrm{ml} / \mathrm{min}$. Mobile phase at time $0: 100 \%$ buffer A $(0.02 \mathrm{M}$ Tris, $100 \mathrm{mg} /$ liter $\mathrm{KCN}, \mathrm{pH} 8.6)$ and $100 \%$ buffer B at $35 \mathrm{~min}$ $(0.02 \mathrm{M}$ Tris, $0.2 \mathrm{M}$ Na acetate, $\mathrm{pH} 7.0)$. Requilibration was accomplished by pumping huffer $\mathrm{A}$ for 10 min. Notice the increased amounts of Hb F II due to aging of the hemolysate. All three samples were separated on the same column.

bris was removed following centrifugation. An aliquot of the hemolysate was immediately utilized for cellulose acetate electrophoresis (9) and the remainder was kept frozen at $-4^{\circ} \mathrm{C}$ for subsequent HPLC analysis. In some cases blood was also collected from other relatives for family studies. Some infants were restudied at 2 to 7 months of age to evaluate changes in the hemoglobin HPLC pattern.

HPLC chromatography. The HPLC system used consisted of a Varian Model 5020 gradient liquid chromatograph (Varian Instruments, Palo Alto, Calif.). The hemolysate was injected onto the column either manually or automatically using an automatic injector (Varian Instruments). Synchropak AX300 (10) ion-exchange columns measuring $4.1 \times 100 \mathrm{~mm}$ were used (Synchrom, Linden, Ind.). The support consisted of a $10-\mu \mathrm{m}$ macroporous spherical silica with a bonded polymeric layer of amine. Initially, columns packed by the manufacturer were utilized. Subsequently, however, because of variability in retention times from batch to batch of ion exchanger, all columns were prepared in the laboratory from the same batch of ion exchanger (11). Elution was accomplished using a linear gradient of buffers $A$ and B. Buffer A consisted of $0.02 \mathrm{M}$ Tris, $100 \mathrm{mg} /$ liter $\mathrm{KCN}$; pH 8.6. Buffer B consisted of $0.02 \mathrm{M}$ Tris, $0.2 \mathrm{M} \mathrm{Na}$ acetate, $\mathrm{pH}$ 7.0. The $\mathrm{pH}$ of all buffers was adjusted with acetic acid. Buffer $A$ was used for equilibration. Initially, several programs with different flow rates and gradient slopes were utilized. Subsequently, however, a 35-min program consisting of $100 \%$ buffer A $10 \%$ buffer B) at time 0 and $100 \%$ buffer B at 35 min with a flow rate of $1.5 \mathrm{ml} / \mathrm{min}$ was utilized. Operating column pressure was 500 psi. Column reequilibration was accomplished by pumping buffer $A$ for $10 \mathrm{~min}$ at a flow rate of $1.5 \mathrm{ml} / \mathrm{min}$. Separation was carried out at room temperature. Absorbance was monitored at $415 \mathrm{~nm}$ with a vari- 


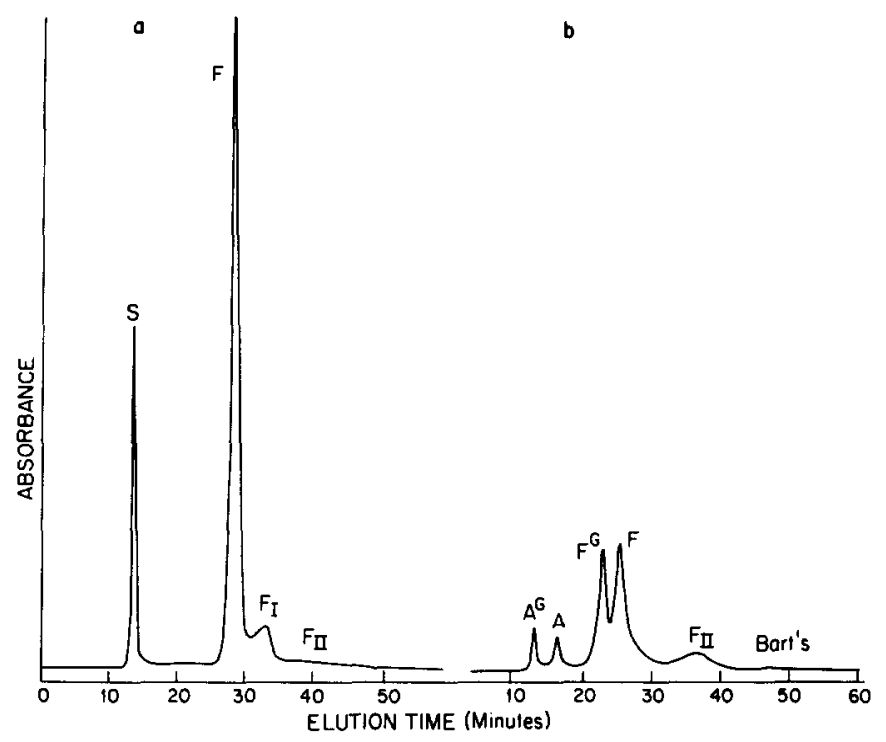

FIG. 2. Chromatographic separation of hemoglobins in hemolysates from (a) a newborn with sickle cell disease and (b) a newborn with $\mathrm{Hb} \mathrm{G}$ Philadelphia. Conditions are the same as in Fig. 1, except a longer 60 -min program was used with $100 \%$ buffer $A$ at time 0 and $50 \%$ buffer $B$ at 60 min with a flow rate of $1.0 \mathrm{ml} / \mathrm{min}$. Notice the small amount of $\mathrm{Hb} \mathrm{F}$ II in (a).

able wavelength detector. The proportion of the separated hemoglobin peaks was computed using a Beckman Model 126 data system (Beckman, Palo Alto, Calif.). Stored hemolysates were diluted fivefold with buffer A, followed by centrifugation at $10,000 \mathrm{~g}$ for $10 \mathrm{~min}$ prior to chromatography. Ten to twenty microliters of the final hemolysate preparation were injected onto the column.

\section{RESULTS}

\section{Elution Pattern}

The order in which various hemoglobins were eluted was similar to that observed with conventional anion-exchange chromatography (Figs. 1-3). By means of a 35-min program with a flow rate of $1.5 \mathrm{ml} / \mathrm{min}$, four major peaks were identified in hemolysates from normal newborns. Hb A was eluted separately, followed by the major $\mathrm{Hb} F$ peak, a $\mathrm{Hb}$ FI shoulder, and a $\mathrm{Hb}$ FII peak. The proportion of the $\mathrm{Hb}$ FII fraction was variable and gradually increased with the aging of the hemolysates. Freshly prepared samples contained approximately $3-5 \%$ of $\mathrm{Hb}$
FII, while hemolysates that had been stored in the refrigerator for 3 to 6 months contained up to $35 \%$ of $\mathrm{Hb}$ FII. Freezing of the hemolysate reduced the effect of aging on

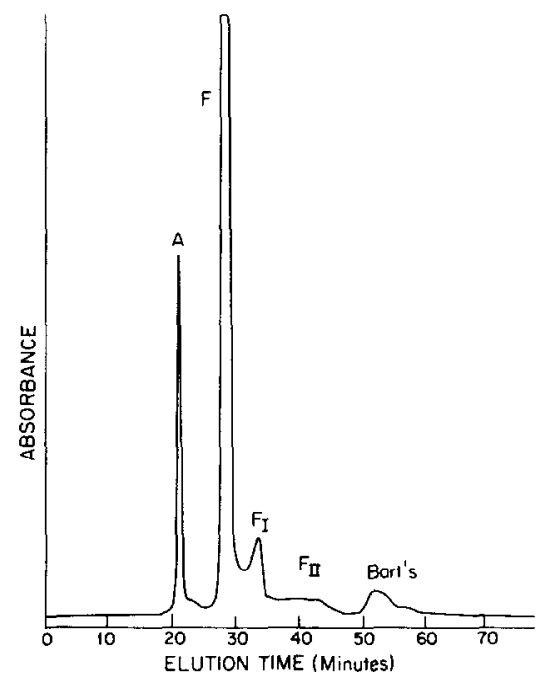

FIG. 3. Chromatographic separation of hemoglobins from a newborn with elevated levels of Bart's $\mathrm{Hb}$. Conditions are the same as in Fig. 2, except a different column was used. A small shoulder is noted following the major Bart's $\mathrm{Hb}$ peak. 
Hb FII but did not eliminate it completely. Dialysis in the presence of $0.5 \%$ 2-mercaptoethanol for 2 to $6 \mathrm{~h}$ was asociated with a reduction in the proportion of $\mathrm{Hb}$ FII. Storage had little effect on the proportion of $\mathrm{Hb}$ FI, which amounted to $8-10 \%$ of the total hemoglobin (Fig. 1). To determine the identity of $\mathrm{Hb} \mathrm{FI,} \mathrm{hemoglobins} \mathrm{in} \mathrm{newborn} \mathrm{hem-}$ olysates were first separated on Bio-Rex columns (12). Each of the hemoglobin fractions collected was subsequently analyzed by ionexchange HPIC. Only the acetylated Hb F fraction collected off the Bio-Rex column had an identical elution time as $\mathrm{Hb}$ FI.

Abnormal samples encountered among 415 newborns studied included 4 FS, 1 FSC, $22 \mathrm{FAS}$, and $4 \mathrm{FAC}$ patterns. Two unrelated infants had an alpha-chain variant identified as $\mathrm{Hb} \mathrm{G}$ Philadelphia by peptide analysis. Hemoglobins A, S, and C when present were eluted separately (Figs. 1 and 2). The proportion of $\mathrm{Hb} \mathrm{S}$ in samples showing a FAS pattern was quite variable. As little as $2 \%$ $\mathrm{Hb} \mathrm{S}$ was present in some hemolysates. Patterns corresponding to newborns with sickle cell anemia did not include any peaks between $S$ and $F$ when fresh hemolysates were used. However, after storage in the refrigerator for 2 to 4 weeks a small peak amounting to $2-4 \%$ of the total hemoglobin was noted in the $\mathrm{Hb} \mathrm{A}$ position. The appearance of this peak was associated with a corresponding decrease in the sizc of the $\mathrm{Hb} S$ peak.

Hemolysates that showed a striking increase in Bart's $\mathrm{Hb}$ by cellulose acetate electrophoresis (6-8\% of the total hemolysate) were utilized to determine the elution time of Bart's $\mathrm{Hb}$ by HPLC. Newborns from whom these hemolysates were obtained had abnormal red blood cell indices indicative of thalassemia. The HPLC pattern for the hemolysates contained a late-eluting peak not present in patterns obtained from normal newborns (Figs. 1-3). The size of the lateeluting peak corresponded well to the amount of Bart's $\mathrm{Hb}$ on cellulose acetate electro- phoresis. The major peak corresponding to Bart's $\mathrm{Hb}$ was followed by a small shoulder when relatively flat gradients were utilized (Fig. 3). The shoulder was less noticeable using the shorter 35-min gradient program (Fig. 1). Of all the newborn hemolysates studied, 33 contained a Bart's Hb peak that represented $1 \%$ or more of the total hemoglobin.

\section{Reproducibility}

The elution time for different hemoglobin types was remarkably constant from run to run using the same column and gradient program and did not differ by more than 0.2 min from the expected value. However, the elution time was quite variable from column to column. For example, in the case of the 35-min program, there was as much as a 5min difference in elution time for a hemoglobin type between columns. The difference was related to the packing material because much less variability was encountered when columns prepared from the same batch of ion exchanger were utilized.

$\mathrm{Hb} \mathrm{G}$ Philadelphia in hemolysates from two newborns and their relatives consistently eluted in the same position, which was 2 min later than $\mathrm{Hb} \mathrm{S}$ with the 35 -min gradient program. This observation, coupled with the presence of two major peaks in the $\mathrm{Hb} \mathrm{F}$ region, clearly indicated the presence of an alpha-chain variant (Fig. 2b). The reproducibility of the technique extends to the quantitation of the different hemoglobin types in hemolysates. The proportion of various hemoglobins did not differ by more than $1 \%$ in 10 consecutive runs of a hemolysate that gave a FAS pattern. The reproducibility is best illustrated in the case of one of the two newborns with $\mathrm{Hb} \mathrm{G}$ Philadelphia who was studied at birth and later at 4 and 7 months of age. Both parents of this infant were also studied (Table 1). The presence of equal amounts of normal and variant $H$ bs $A$ and $F$, coupled with increased amounts 
TABLE 1

Quantitation of Hemoglobin Types In Hemolysates from a Family WITH HEMOgLoBIN G PHILADELPHIA

\begin{tabular}{lcccccccc}
\hline Subject & $\begin{array}{c}\mathrm{G}_{2} \\
(\%)\end{array}$ & $\begin{array}{c}\mathrm{A}_{2} \\
(\%)\end{array}$ & $\begin{array}{c}\mathrm{G} \\
(\%)\end{array}$ & $\begin{array}{c}\mathrm{A} \\
(\%)\end{array}$ & $\begin{array}{c}\mathrm{F} / \mathrm{G} \\
(\%)\end{array}$ & $\begin{array}{c}\mathrm{F} \\
(\%)\end{array}$ & $\begin{array}{c}\text { Bart's } \\
(\%)\end{array}$ & $\begin{array}{c}\text { Total G } \\
(\%)\end{array}$ \\
\hline Infant & & & & & & & & \\
$\quad$ Cord blood & - & - & 5.8 & 7.2 & 38.2 & 46.3 & 2.5 & 44.0 \\
$\quad$ 4 Mos & 1.0 & 1.1 & 40.4 & 43.1 & 5.8 & 8.6 & - & 47.2 \\
7 Mos & 1.0 & 1.4 & 43.6 & 46.2 & 3.8 & 4.0 & - & 48.4 \\
Father & 0.8 & 1.6 & 34.5 & 60.3 & - & 2.8 & - & 35.5 \\
Mother & - & 2.1 & - & 95.0 & - & 2.9 & - & - \\
\hline
\end{tabular}

of Bart's $\mathrm{Hb}$ at birth was strongly suggestive of a homozygous state for a deletion of one of the two active alpha genes in the infant ( $\alpha^{\mathrm{G}}-/ \alpha$-genotype). The smaller proportion of HB G Philadelphia in the father was suggestive of a deletion of one of the four alpha genes $\left(\alpha^{\mathrm{G}}-/ \alpha \alpha\right.$-genotype). It was therefore concluded that the infant's mother had an alpha gene deletion to account for the presence of only two active alpha genes in the infant. These conclusions, based on the HPLC quantitation of the normal and variant hemoglobins, were confirmed by restriction endonuclease mapping of the alpha globin genes (13).

The proportion of Bart's $\mathrm{Hb}$ in hemolysates containing increased amounts of this hemoglobin did not appreciably decrease even after several months of storage of the hemolysates, if they were kept frozen at $-4^{\circ} \mathrm{C}$. However, quantitation of small amounts of Bart's $\mathrm{Hb}$ (less than 1\%) was not reproducible in multiple runs.

It is noteworthy that in the two cases of Hb G Philadelphia, the presence of an alphachain variant was missed by electrophoresis because there was no splitting of the $\mathrm{Hb} \mathrm{F}$ band and the only abnormal $\mathrm{Hb}$ band noted was in the $\mathrm{Hb} \mathrm{S}$ position. In addition, a $\mathrm{Hb} \mathrm{A}$ band in four individuals who had a FAS pattern by HPLC was not obvious by electrophoresis because of poor resolution from $\mathrm{Hb} \mathrm{F}$.

\section{DISCUSSION}

Screening for abnormal hemoglobins in the newborn period differs from screening in other age groups because of the presence of large amounts of $\mathrm{Hb} \mathrm{F}$ and the need to detect and quantitate Bart's $\mathrm{Hb}$, which is only transiently increased at birth in alpha thalassemia. In contrast, quantitation of the small amounts of $\mathrm{Hb} \mathrm{A2,} \mathrm{which} \mathrm{is} \mathrm{increased}$ in beta-thalassemia, is an important part of screening in the older group but not in the newborn period. $\mathrm{Hb} \mathrm{A} 2$ is an early eluting peak, whereas Bart's $\mathrm{Hb}$ is the last peak to come off the column. Consequently, HPLC analysis of hemoglobins in the newborn period requires the use of gradient programs different from those used for the older age group. Adequate resolution was achieved using a higher ionic strength for buffer B and a higher flow rate than have been used before $(14,15)$.

Several factors have an important effect on the separation of hemoglobins by ion-exchange HPLC. These have been discussed in detail elsewhere (14). In particular, the use of columns prepared from different batches of ion exchanger requires slight modifications in the gradient program to ensure optimal resolution. Obviously, it is necessary to use hemoglobin standards with every new column to establish the elution time of different hemoglobin types. 
The results described above indicate that hemoglobin analysis by ion-exchange HPLC combines the advantages of several other techniques. This includes excellent separation of hemoglobins $\mathrm{A}, \mathrm{S}$, and F. Furthermore, the elution time for $\mathrm{Hb} \mathrm{S}$ was different from that of $\mathrm{Hb} \mathrm{G}$ Philadelphia. Also, in a previous study, Hb D Punjab differed in its elution time from $\mathrm{Hb} \mathrm{S}$.

Bart's $\mathrm{Hb}$ eluted as a distinct peak even with the short 35 -min gradient program. The importance of quantitating Bart's $\mathrm{Hb}$ in the newborn period is emphasized by recent studies utilizing restriction endonuclease mapping of alpha globin genes. It has been demonstrated that more than $25 \%$ of American blacks have a heterozygous alpha-thalassemia-2 genotype $(-\alpha / \alpha \alpha)$ with an expected frequency of the homozygous state of 2 to $3 \%$ (16). While the heterozygous state might not necessarily be associated with increased amounts of Bart's $\mathrm{Hb}$, the presence of morc than $2 \%$ Bart's $\mathrm{Hb}$ in black newborns has been found to be indicative of a homozygous alpha-thalassemia- 2 state $(-\alpha /-\alpha)(17,18)$.

The importance of counseling and followup evaluations of newborns with abnormal patterns, as essential components of a screening program, has previously been emphasized (19). For example, all four newborns with a FS pattern by HPLC had subsequent evaluations, including family studies, that confirmed the diagnosis of sickle cell anemia.

Most screening programs involve large numbers of samples. Therefore, the potential for automation of HPLC, coupled with excellent reproducibility, makes this technique ideally suited for the detection of hemoglobin disorders in the newborn period.

\section{REFERENCES}

1. Evans, D. I. K., and Carmel', A. (1976) Arch. Dis. Childhood 51, 127-130.
2. Pearson, H. A., O'Brien, R. T., McIntosh, S., Aspnes, G. T., and Yang, M. (1974) J. Amer. Med. Assoc. 227, 420-421.

3. Sexauer, C. L., Graham, H. L., Starling, K. A., and Fernbach, D. J. (1976) Amer. J. Dis. Child. 130, 805-806.

4. Serjeant, B. E., Forbes, M., Williams, L. L., and Serjeant, G. R. (1974) Clin. Chem. 20, 666-669.

5. Powars, D., Schroeder, W. A., and White, L. (1975) Pediatrics 55, 630-635.

6. Galacteros, F., Kleman, K., Cabari-Martin, J., Beuzard, Y., Rosa, J., and Lubin, B. (1980) Blood 56, 1068-1071.

7. Beuzard, Y., Galacteros, F., Braconnier, F., Dubart, A., Chen-Marotel, J., Caburi-Martin, J., Monplaisir, N., Sellaye, M., Martin, C. S., Seytor, S., Bassett, P., and Rosa, J. (1981) in Advances in Hemoglobin Analysis (Hanash, S. M., and Brewer, G. J., eds.), pp. 177-195, Alan R. Liss, New York.

8. Hanash, S. M., and Shapiro, D. N. (1980) $\mathrm{He}$ moglobin 5(2), 165-175.

9. Huisman, T. H. J., and Jonxis, J. H. P. (1977) The Hemoglobinopathies. Techniques of Identification, 105, Dekker, New York.

10. Gooding, K. M., Lu, K. C., and Regnier, F. E. (1979) J. Chromatogr. 164, 506-509.

11. Broquaire, M. (1979) J. Chromatogr. 170, 43-52.

12. Abraham, E. C., Cope, N. D., Braziel, N. N., and Huisman, T. H. J. (1979) Biochim. Biophys. Acta 577, 159-169.

13. Jeffereys, A. J., and Flavell, R. A. (1977) Cell 12, 429-439.

14. Hanash, S. M., Kavadella, M., Amanulla, A., Scheller, K., and Bunnell, K. (1981) in Advances in Hemoglobin Analysis (Hanash, S. M., and Brewer, G. J., eds.), pp. 53-67, Alan R. Liss, New York.

15. Huisman, T. H. J., Gardiner, M. B., and Wilson, J. B. (1981) in Advances in Hemoglobin Analysis (Hanash, S. M., and Brewer, G. J., eds.), pp. 6982, Alan R. Liss, New York.

16. Dozy, A. M., Kan, Y. W., Embury, S. H., Mentzer, W. C., Yang, W. C., Lubin, B., Davis, J. R., Jr., and Koenig, H. M. (1979) Nature (London) 280 , 605-607.

17. Higgs, D. R., Pressley, L., Clegg, J. B., Weatherall, D. J., and Serjeant, G. R. (1980) Johns Hopkins Med. J. 146, 300-310.

18. Ohene-Frempong, K., Rappaport, E., Atwater, J., Schwartz, E., and Surrey, S. (1980) Blood 56, 931-933.

19. Miller, D. R. (1979) Amer. J. Dis. Child. 133, 1235-1236. 